\title{
Symphysis-pubis fundal height charts to assess fetal size in women with a normal body mass index
}

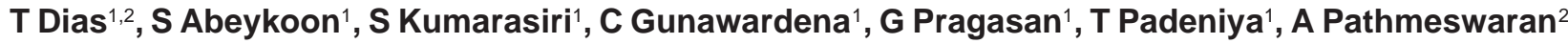 \\ (Index words: symphysis-pubis fundal height charts, normal BMI, Sri Lanka)
}

\begin{abstract}
Objectives To construct symphysis-pubis fundal height (SFH) charts to estimate fetal size in pregnant women with a normal body mass index (BMI) and to describe the variation of SFH measurements according to BMI.

Methods A cross sectional study was carried out at Ampara and Gampaha Districts in Sri Lanka. Women with normal nutritional and health status, normal BMI and minimal environmental constraints on fetal growth, with ultra sound confirmation of dates by fetal crown-rump length measurements between 11 weeks and 13 weeks + six days, had their SFH measured, using non-elastic tape and standard techniques, between 24 and 41 weeks gestation. Only one measurement of SFH was obtained from each pregnant woman. Linear and polynomial regression models were fitted separately to the means and standard deviations (SD) as functions of gestational age to identify the model with the best fit. Centiles were derived from the mean and SD at each gestational age.

Results Pregnant women from the districts of Ampara $(n=387)$ and Gampaha $(n=200)$ were recruited. Other than a difference of $-1.5 \mathrm{~cm}(95 \% \mathrm{Cl}-2.27$ to -0.23$)$ at 38 weeks of gestation, there were no significant differences between the SFH measurements obtained from women with normal BMI in Ampara and Gampaha Districts. Using the SFH measurements from the Ampara sample, charts were created for 10th, 50th and 90th centile values of $\mathrm{SFH}$. At 40 weeks of gestation these were $34 \mathrm{~cm}, 37 \mathrm{~cm}$ and $41 \mathrm{~cm}$ respectively. At 40 weeks gestation, the variation in SFH measurements between BMl sub groups within the normal range was approximately $1.4 \mathrm{~cm}$ to $1.6 \mathrm{~cm}$.

Conclusions These SFH charts could be used to estimate fetal size in pregnant women with normal BMI.
\end{abstract}

Ceylon Medical Journal 2016; 61: 106-112

DOI: http://doi.org/10.4038/cmj.v61i3.8345

\section{Introduction}

Abnormal fetal growth is responsible for most of the explained and unexplained intra-uterine fetal deaths [1]. Abnormal fetal growth could be small for gestational age (SGA) where fetal size is below the 10th centile or large for gestational age (LGA) where fetal size is above the 90th centile. Uteroplacental insufficiency carries a higher risk of adverse fetal outcomes but it is only responsible for a proportion of SGA. Constitutional delay and fetal aneuploidy are other reasons for SGA. Antenatal fetal growth assessment is intended to identify the fetus at risk of growth restriction [2]. Clinical estimation of the fetal size by palpating the woman's abdomen, measurement of symphysis-fundal height (SFH) and ultrasound assessment of fetal biometry are some of the recognised tools for assessing fetal size and growth [3].

Serial assessment of SFH is a cost effective method of screening for abnormalities of fetal growth. It is recommended that the SFH is routinely measured and recorded at each antenatal appointment from 24 weeks onwards [2]. In a fetus which is growing normally, the SFH measurement in centimeters should approximately correspond to the gestation [4]. However the variance increases with increasing gestational age and the range of plus or minus 2 centimeters at 24 weeks gestation is increased to plus or minus 4 centimeters at 40 weeks gestation, with the measurement very often being less than the corresponding weeks of gestation [5]. It has been recommended that a single SFH measurement which plots below the 10th centile or serial measurements which demonstrate slow or static growth should be referred for further investigation [3].

Although SFH assessment has been used for more than four decades, it has been demonstrated that the body stature and the length of a woman's abdomen could significantly affect its reliability [6]. Furthermore, interand intra-observer variations are bound to occur in such measurements. However, reproducibility of repeated

${ }^{1}$ District General Hospital, Ampara and 2Faculty of Medicine, University of Kelaniya, Sri Lanka.

Correspondence: TD, <thiran_dias@yahoo.com>. Received 4 November 2015 and revised version accepted 29 April 2016.

This is an open-access article distributed under the terms of the Creative Commons Attribution License, which permits unrestricted use, distribution, and reproduction in any medium, provided the original author and source are credited. 
measurements of SFH has been reported [7]. While body mass index (BMI) and parity are known to greatly influence the SFH, high false positive rates of SGA are seen among South Asian women [4]. In a recent study, the fetal growth of representative samples from eight different countries was carefully monitored. Results showed that differences in linear fetal growth during pregnancy were minimal under optimal conditions, indicating that ethnicity may not affect the fetal growth in a significant manner [8]. However, fetal size and SFH measurements vary significantly even with different individual BMIs within the normal range of BMI as well as different combinations of height and weight resulting in the same BMI $[9,10]$. Although individually customised charts are used in many wellresourced centres it would be difficult to create customised SFH charts for each patient in an antenatal clinic with a heavy work load. Hence the need for the development of SFH charts customised according to at least two groups of low and normal BMI, for use in Sri Lanka, has been stressed earlier [11].

SFH size charts based on cross sectional data are considered to be the best when a single measurement is considered at a given time [3]. There is a paucity of evidence of the optimum SFH measurement for each gestational age in low and middle income countries where its use may be most valuable. The objectives of this study were to construct symphysis-pubis fundal height (SFH) charts to estimate the fetal size in pregnant women with a normal $\mathrm{BMI}$ and to describe the variation of SFH according to $\mathrm{BMI}$ in women within the normal range of BMI.

\section{Methods}

This cross-sectional study was carried out at Ampara and Gampaha Districts between January 2013 and February 2015. We enrolled women who initiated antenatal care before 14 weeks of gestation with normal nutritional and health status and minimal environmental constraints on fetal growth at each study site (Table 1). All pregnancies with first trimester ultrasound Crown- Rump Length (CRL) dating were included [12]. Inclusion criteria of the study population are given in table 1. Altman and Chitty have suggested that at least 300 observations would be necessary to get reasonable estimates [13]. The SFH measurements obtained from women in Ampara were compared with those of the Gampaha. Using Altman and Chitty's statistical methods, SFH charts to estimate fetal size in pregnant women with a normal BMI as well as for sub-groups of BMI (Low normal 18.5-20.0 kg/m² and High normal $23-25 \mathrm{~kg} / \mathrm{m}^{2}$ ) within the normal range of BMI, were constructed from the SFH measurements in the women from Ampara [13].

SFH measurements were obtained by two trained doctors, one for each study site, using a non-elastic tape. The expectant mothers were in supine position on a firm surface, with an empty bladder. SFH was measured from the fundus (variable point) to the symphysis pubis (fixed point) along the longitudinal axis of the uterus with centimeter markings facing the mother's abdomen and thus being not visible during the measurement [14]. The two trained doctors who carried out the measurements were blinded to the period of gestation. Only one measurement of SFH was obtained from each woman.

\section{Table 1. Eligibility criteria used for selecting the population}

- $\quad$ BMI $\geq 18.5$ and $<25 \mathrm{~kg} / \mathrm{m}^{2}$

- $\quad$ Singleton pregnancy

- Natural conception

- $\quad$ No relevant past medical history, not on long term medication

- $\quad$ No evidence of socio-economic constraints likely to impede fetal growth

- No use of tobacco or recreational drugs, alcohol use

- $\quad$ No more than one miscarriage in the three previous consecutive pregnancies

- $\quad$ No previous baby delivered pre-term ( $<37$ weeks) or with a birth weight $<2500$ g or $>4500$ g

- No previous pregnancy affected by pre-eclampsia/ eclampsia, HELLP syndrome or a related pregnancyassociated condition

- No clinically significant atypical red cell alloantibodies

- $\quad$ No evidence of urinary tract infection or renal disease on urinalysis

- $\quad$ Systolic blood pressure $<140 \mathrm{mmHg}$ and diastolic blood pressure $<90 \mathrm{mmHg}$

- $\quad$ No diagnosis or treatment for anemia during this pregnancy

- Not in an occupation with risk of exposure to chemicals or toxic substances

The mean differences between the SFH measurements in the women from Ampara and Gampaha and their standard errors (SE) of the means were calculated and compared for each gestational age between 24 and 40 weeks. Systematic error was assumed to exist if zero lay outside the mean difference \pm 2 SE. Linear and polynomial regression models were fitted separately to the means and standard deviations (SD) as functions of gestational age to identify the model with the best fit [13]. The centiles were obtained making the assumption that at each gestational age the measurements had a normal distribution.

Approval was obtained from the Ethics Review Committees of the District General Hospital, Ampara and the Faculty of Medicine University of Kelaniya. Informed written consent was obtained from all participants.

\section{Results}

A total of 4256 women ( $n=3100$ from Ampara District and $n=1156$ from Gampaha District) with confirmed ultrasound dating were screened to recruit women with 
normal nutritional and health status and minimal environmental constraints on fetal growth. Three hundred and eighty seven pregnant women from the Ampara District and 200 pregnant women from the Gampaha were selected for the study. There were no significant differences in basic characteristics between the women recruited from Ampara and Gampaha (Table 2). Although the mean SFH at 38 weeks of gestation in the women from Ampara was $1.5 \mathrm{~cm}$ less (95\% CI -2.27 to $-0.23, p<0.05$ ) than that of the women from Gampaha at 38 weeks of gestation, there were no other significant differences between the SFH measurements obtained from normal BMI women in Ampara and Gampaha districts (Table 3.)

Table 4 shows the measurements of the women from Ampara. The duration of gestation was rounded off to the completed weeks of gestation (eg. 34 weeks and six days $=34$ weeks). Linear regression models giving the best fit for mean SFH measurement according to the weeks of gestation were used to create centile charts.

The normal scatter plot of SFH against the weeks of gestation (Figure 1) as well as the plot of the standardised residuals against the weeks of gestation, showed that the SFH measurements at each gestational age had a normal distribution and this enabled the $10^{\text {th }}, 50^{\text {th }}$ and $90^{\text {th }}$ centiles to be obtained for the total sample of women from Ampara (Table 5 and Figure 2).

Table 6 describes the variation of SFH measurements between subgroups of BMI (Low normal 18.5-20.0 kg/m² mid normal $20.1-22.9 \mathrm{~kg} / \mathrm{m}^{2}$ and high normal $23-25 \mathrm{~kg} / \mathrm{m}^{2}$ ) within the normal range of BMI. Figures 3-5 show the estimated centiles for each gestation for these subgroups of BMI.

Table 2. Characteristics of the study population

\begin{tabular}{lccc}
\hline & Ampara & Gampaha & Significance \\
\hline & Number (\%) & Number (\%) & \\
\hline Ethnicity & & & \\
$\quad$ Sinhalese & $356(92)$ & $184(92)$ & 6.6831 \\
$\quad$ Muslims & $23(6)$ & $6(3)$ & \\
$\quad$ Tamils & $8(2)$ & $2(1)$ & \\
$\quad$ Burgher & & $2(1)$ & $p=0.973$ \\
\hline Parity & $2(1)$ & 27.9 & $p .2671$ \\
$\quad$ Median (IQR) & 28.4 & $(5.3)$ & $p=0.0631$ \\
\hline Mean age years (SD) & $(5.1)$ & 21.13 & \\
& 21.45 & $(1.7)$ & \\
\hline Mean BMI (SD) & $(2.1)$ & & \\
& & & \\
\hline
\end{tabular}

Table 3. Comparison of data from Ampara and Gampaha

\begin{tabular}{|c|c|c|c|c|c|c|c|c|}
\hline \multirow[b]{2}{*}{$\begin{array}{l}\text { Gestational } \\
\text { age (weeks) }\end{array}$} & \multicolumn{2}{|c|}{ Ampara } & \multicolumn{4}{|c|}{ Gampaha } & \multirow{2}{*}{$\begin{array}{c}\text { Estimated difference } \\
\text { between the two } \\
\text { population means }\end{array}$} & \multirow{2}{*}{$\begin{array}{c}\text { Estimated } 95 \% \\
\text { CI in two } \\
\text { populations }\end{array}$} \\
\hline & $N$ & $\begin{array}{c}\text { Mean } \\
\text { SFH }\end{array}$ & $S D$ & $N$ & $\begin{array}{l}\text { Mean } \\
\text { SFH }\end{array}$ & $S D$ & & \\
\hline 24 & 25 & 23.7 & 2.9 & 20 & 24.2 & 2.8 & -0.5 & -2.23 to 1.23 \\
\hline 26 & 23 & 25.5 & 2.0 & 20 & 25.9 & 2.0 & -0.4 & -1.63 to 0.83 \\
\hline 28 & 17 & 26.8 & 1.4 & 20 & 27.6 & 1.3 & -0.8 & -1.7 to 0.10 \\
\hline 30 & 15 & 28.3 & 3.1 & 20 & 29.0 & 1.6 & -0.7 & -2.34 to 0.94 \\
\hline 32 & 22 & 31.7 & 2.1 & 20 & 31.6 & 2.4 & 0.1 & -1.3 to 1.5 \\
\hline 34 & 29 & 32.4 & 2.3 & 20 & 33.0 & 1.7 & -0.6 & -1.82 to 0.62 \\
\hline 36 & 22 & 34.4 & 2.6 & 20 & 35.4 & 1.0 & -1 & -2.25 to 0.25 \\
\hline 38 & 27 & 35.5 & 2.5 & 20 & 37.0 & 1.5 & -1.5 & -2.27 to $-.23 *$ \\
\hline 40 & 23 & 37.1 & 2.4 & 20 & 37.6 & 1.7 & -0.5 & -1.8 to 0.80 \\
\hline
\end{tabular}

SFH = Symphysis-pubis fundal height, SD = standard deviation

* Systematic error was assumed to exist if zero lay outside the estimated 95\% CI in two populations 
Table 4. The symphysis-pubis fundal height measurements in centimeters, at each week of gestation in all the women with normal BMI in the Ampara District

\begin{tabular}{|c|c|c|c|c|c|c|}
\hline $\begin{array}{c}\text { Period of } \\
\text { gestation } \\
\text { (weeks) }\end{array}$ & $\begin{array}{c}n \\
(=387)\end{array}$ & Median & Mean & $\begin{array}{l}\text { Standard } \\
\text { deviation }\end{array}$ & Maximum & Maximum \\
\hline 24 & 24 & 24.0 & 23.3 & 2.4 & 19.0 & 29.0 \\
\hline 25 & 23 & 25.0 & 24.8 & 1.6 & 22.0 & 27.0 \\
\hline 26 & 23 & 25.0 & 25.5 & 2.0 & 22.0 & 30.0 \\
\hline 27 & 22 & 27.0 & 26.5 & 2.3 & 22.0 & 31.0 \\
\hline 28 & 17 & 27.0 & 26.8 & 1.4 & 24.0 & 29.0 \\
\hline 29 & 25 & 27.0 & 27.1 & 2.8 & 22.0 & 33.0 \\
\hline 30 & 15 & 29.0 & 28.3 & 3.1 & 22.0 & 32.0 \\
\hline 31 & 15 & 29.0 & 29.7 & 2.3 & 27.0 & 34.0 \\
\hline 32 & 22 & 32.0 & 31.7 & 2.1 & 28.0 & 35.0 \\
\hline 33 & 23 & 30.0 & 30.6 & 2.5 & 26.0 & 35.0 \\
\hline 34 & 29 & 32.0 & 32.4 & 2.3 & 28.0 & 37.0 \\
\hline 35 & 29 & 33.0 & 32.6 & 2.5 & 28.0 & 37.0 \\
\hline 36 & 20 & 34.0 & 34.3 & 2.7 & 30.0 & 41.0 \\
\hline 37 & 30 & 34.0 & 33.5 & 3.6 & 23.0 & 39.0 \\
\hline 38 & 27 & 35.0 & 35.5 & 2.5 & 31.0 & 41.0 \\
\hline 39 & 11 & 38.0 & 36.2 & 3.5 & 31.0 & 41.0 \\
\hline 40 & 23 & 37.0 & 37.1 & 2.4 & 33.0 & 42.0 \\
\hline 41 & 9 & 37.0 & 37.2 & 2.0 & 34.0 & 41.0 \\
\hline
\end{tabular}

Table $5.10^{\text {th }}, 50^{\text {th }}$ and $90^{\text {th }}$ centiles of symphysis-pubis fundal height measurements at each gestation between 24 and 41 weeks in all the women with normal $B M I$ in the Ampara District $(n=387)$

\begin{tabular}{|c|c|c|c|c|}
\hline \multirow{2}{*}{$\begin{array}{l}\text { Period of } \\
\text { gestation } \\
\text { (weeks) }\end{array}$} & \multicolumn{4}{|c|}{ Symphysis-pubis fundal height (cm) } \\
\hline & 10th Centile & 50th centile & 90th Centile & $S D$ \\
\hline 24 & 21.0 & 23.7 & 26.4 & 2.1 \\
\hline 25 & 21.8 & 24.5 & 27.3 & 2.2 \\
\hline 26 & 22.5 & 25.4 & 28.2 & 2.2 \\
\hline 27 & 23.3 & 26.2 & 29.1 & 2.3 \\
\hline 28 & 24.1 & 27.0 & 30.0 & 2.3 \\
\hline 29 & 24.8 & 27.8 & 30.9 & 2.3 \\
\hline 30 & 25.6 & 28.7 & 31.7 & 2.4 \\
\hline 31 & 26.4 & 29.5 & 32.6 & 2.4 \\
\hline 32 & 27.1 & 30.3 & 33.5 & 2.5 \\
\hline 33 & 27.9 & 31.1 & 34.4 & 2.5 \\
\hline 34 & 28.7 & 32.0 & 35.3 & 2.6 \\
\hline 35 & 29.4 & 32.8 & 36.2 & 2.6 \\
\hline 36 & 30.2 & 33.6 & 37.0 & 2.7 \\
\hline 37 & 31.0 & 34.4 & 37.9 & 2.7 \\
\hline 38 & 31.7 & 35.3 & 38.8 & 2.8 \\
\hline 39 & 32.5 & 36.1 & 39.7 & 2.8 \\
\hline 40 & 33.3 & 36.9 & 40.6 & 2.9 \\
\hline 41 & 34.0 & 37.7 & 41.5 & 2.9 \\
\hline
\end{tabular}




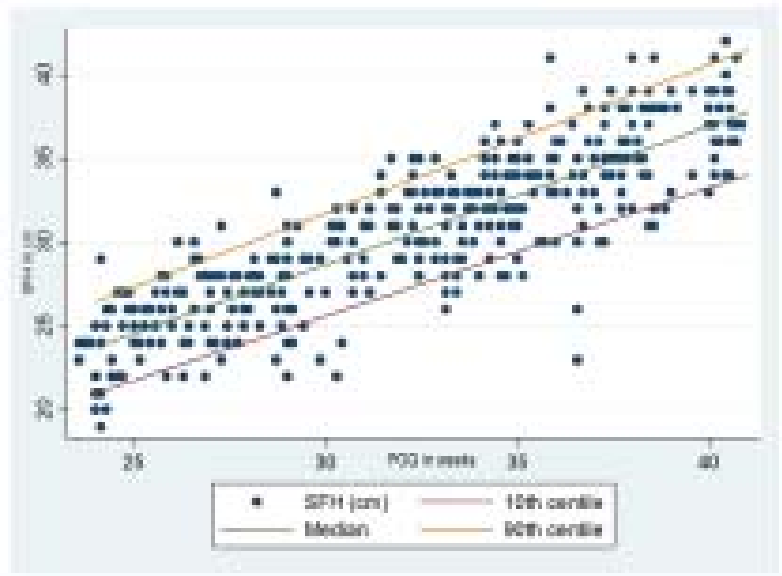

POG $=$ Period of gestation

$\mathrm{SFH}=$ Symphysis-pubis fundal height

Figure 1. Symphysis-pubis fundal height measurements according to the period of gestation in all the women with normal BMI in the Ampara District $(n=387)$.

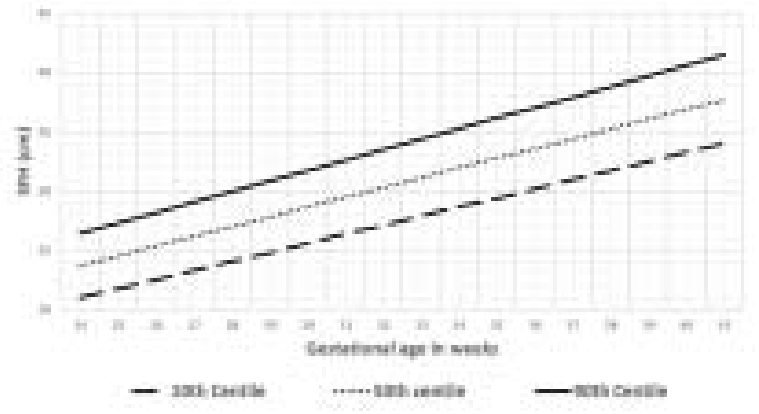

SFH $=$ Symphysis-pubis fundal height

Figure 2. Centile charts of symphysis-pubis fundal height measurements in all the women with normal BMI in the Ampara District $(n=387)$.

Table 6. Variation of SFH measurements between the subgroups of BMI within the normal range of BMI in the women in the Ampara District $(n=387)$

\begin{tabular}{|c|c|c|c|c|c|c|c|c|c|}
\hline \multirow[t]{2}{*}{$\begin{array}{l}\text { Period of } \\
\text { gestation } \\
\text { (weeks) }\end{array}$} & \multicolumn{3}{|c|}{$\begin{array}{c}\text { Low BMI group } \\
18.5-20.0 \mathrm{~kg} / \mathrm{m}^{2} \\
(n=129)\end{array}$} & \multicolumn{3}{|c|}{$\begin{array}{c}\text { Middle BMI group } \\
20.0-23.0 \mathrm{~kg} / \mathrm{m}^{2} \\
(n=147)\end{array}$} & \multicolumn{3}{|c|}{$\begin{array}{l}\text { High BMI group } \\
23.0-25 \mathrm{~kg} / \mathrm{m}^{2} \\
(n=111)\end{array}$} \\
\hline & $\begin{array}{c}10^{\text {th }} \\
\text { Centile }\end{array}$ & $\begin{array}{c}50^{\text {th }} \\
\text { Centile }\end{array}$ & $\begin{array}{c}90^{\text {th }} \\
\text { Centile }\end{array}$ & $\begin{array}{c}10^{\text {th }} \\
\text { Centile }\end{array}$ & $\begin{array}{c}5^{\text {th }} \\
\text { Centile }\end{array}$ & $\begin{array}{c}90^{\text {th }} \\
\text { Centile }\end{array}$ & $\begin{array}{c}10^{t h} \\
\text { Centile }\end{array}$ & $\begin{array}{c}50^{\text {th }} \\
\text { Centile }\end{array}$ & $\begin{array}{c}90^{\text {th }} \\
\text { Centile }\end{array}$ \\
\hline 24 & 21.1 & 23.7 & 26.4 & 21.0 & 23.7 & 26.3 & 21.0 & 23.9 & 26.8 \\
\hline 25 & 21.8 & 24.5 & 27.2 & 21.8 & 24.5 & 27.2 & 21.8 & 24.7 & 27.7 \\
\hline 26 & 22.5 & 25.3 & 28.0 & 22.6 & 25.3 & 28.1 & 22.6 & 25.6 & 28.6 \\
\hline 27 & 23.2 & 26.1 & 28.9 & 23.3 & 26.2 & 29.0 & 23.5 & 26.5 & 29.5 \\
\hline 28 & 24.0 & 26.8 & 29.7 & 24.1 & 27.0 & 29.9 & 24.3 & 27.3 & 30.4 \\
\hline 29 & 24.7 & 27.6 & 30.5 & 24.9 & 27.8 & 30.7 & 25.1 & 28.2 & 31.3 \\
\hline 30 & 25.4 & 28.4 & 31.4 & 25.6 & 28.6 & 31.6 & 25.9 & 29.0 & 32.2 \\
\hline 31 & 26.2 & 29.2 & 32.2 & 26.4 & 29.4 & 32.5 & 26.7 & 29.9 & 33.1 \\
\hline 32 & 26.9 & 30.0 & 33.0 & 27.1 & 30.3 & 33.4 & 27.5 & 30.8 & 34.0 \\
\hline 33 & 27.6 & 30.7 & 33.9 & 27.9 & 31.1 & 34.3 & 28.4 & 31.6 & 34.9 \\
\hline 34 & 28.3 & 31.5 & 34.7 & 28.7 & 31.9 & 35.2 & 29.2 & 32.5 & 35.8 \\
\hline 35 & 29.1 & 32.3 & 35.5 & 29.4 & 32.7 & 36.1 & 30.0 & 33.4 & 36.7 \\
\hline 36 & 29.8 & 33.1 & 36.4 & 30.2 & 33.6 & 36.9 & 30.8 & 34.2 & 37.6 \\
\hline 37 & 30.5 & 33.9 & 37.2 & 31.0 & 34.4 & 37.8 & 31.6 & 35.1 & 38.5 \\
\hline 38 & 31.2 & 34.6 & 38.0 & 31.7 & 35.2 & 38.7 & 32.4 & 35.9 & 39.4 \\
\hline 39 & 32.0 & 35.4 & 38.9 & 32.5 & 36.0 & 39.6 & 33.2 & 36.8 & 40.4 \\
\hline 40 & 32.7 & 36.2 & 39.7 & 33.3 & 36.9 & 40.5 & 34.1 & 37.7 & 41.3 \\
\hline 41 & 33.4 & 37.0 & 40.5 & 34.0 & 37.7 & 41.4 & 34.9 & 38.5 & 42.2 \\
\hline
\end{tabular}




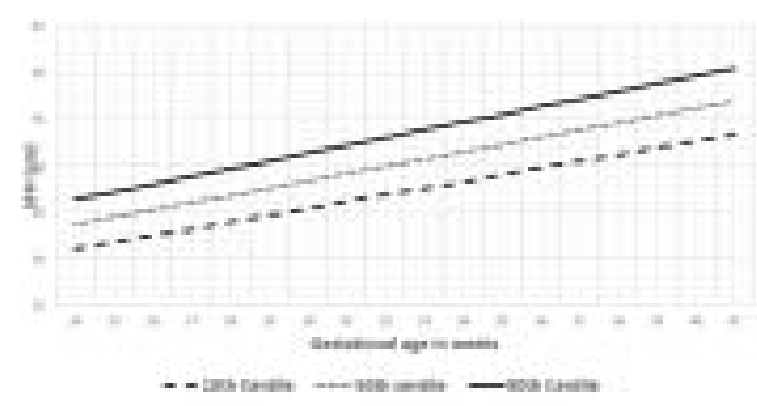

SFH = Symphysis-pubis fundal height

Figure 3. Centile charts of symphysis-pubis fundal height measurements subgroup with lower, normal BM $\left(18.5-20.0 \mathrm{~kg} / \mathrm{m}^{2}\right)$

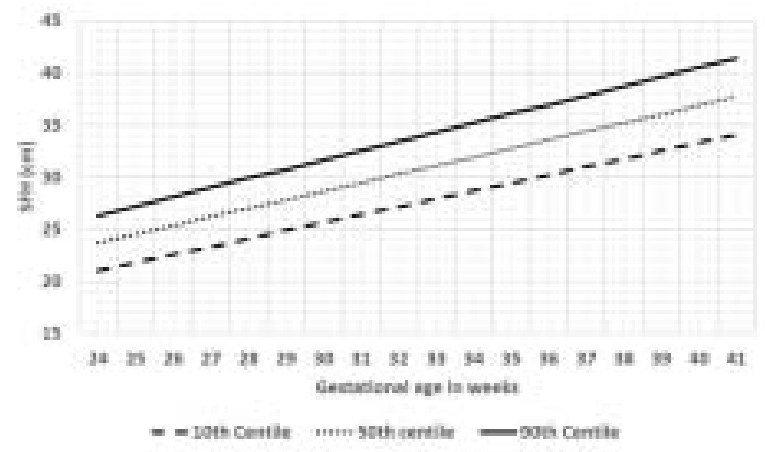

SFH $=$ Symphysis-pubis fundal height

Figure 4. Centile charts of symphysis-pubis fundal height measurements subgroup with middle, normal BM (20-23 kg/m²).

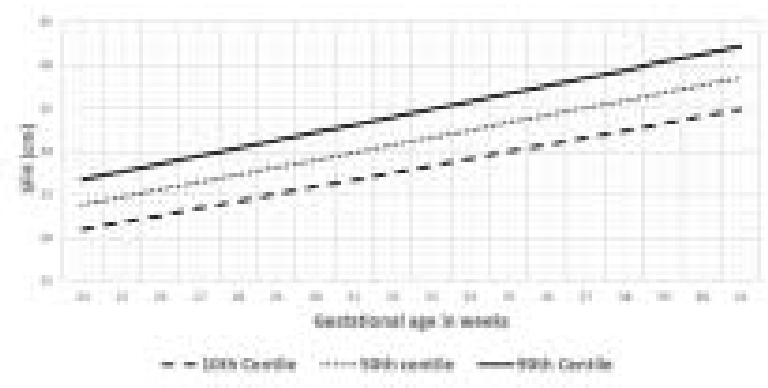

SFH $=$ Symphysis-pubis fundal height

Figure 5. Centile charts of symphysis-pubis fundal height measurements in the subgroup with higher, normal BMI (23-25 kg/m²)

\section{Discussion}

The main chart developed from this study could be used to assess the SFH measurements and the probable fetal size in pregnant women with normal BMI. However the use of three separate charts for each subgroup within the normal BMI would be preferable especially in pregnant women whose BMIs are towards the lower limit or upper limit of the normal range of BMI.
The main strength of our study is that we adopted strict inclusion criteria to select women not only having a normal BMI but also having normal nutritional and health status and minimal environmental constraints on fetal growth. It has been suggested that when maternal social, physical and environmental characteristics are optimised, fetal growth would be similar in different populations [15]. As the actual differences in SFH measurements were less than $1 \mathrm{~cm}$ and there were no significant differences in SFH measurements between women from Ampara and Gampaha from 24 to 34 weeks gestation, the data from Ampara were used to construct the SFH charts and centiles.

We have used statistical methods which take into consideration the changing variability with increasing gestation, and carefully assessed the goodness of fit of the models obtained [13]. Our results show that the 10th 90th centile value for SFH at 40 weeks was $33 \mathrm{~cm}$ and the 90th centile value was $41 \mathrm{~cm}$. This is markedly different from the expected upper and lower limits of SFH at 40 weeks gestation in the chart currently used in antenatal care in Sri Lanka. The values of the chart used currently are $37 \mathrm{~cm}$ lower limit and $43 \mathrm{~cm}$ upper limit although the more accepted lower limit is $36 \mathrm{~cm}$. A recent study recommended a chart developed for women of Indian origin in the United Kingdom (UK) for use in Sri Lanka until customised SFH charts are developed for Sri Lanka [11]. According to that chart, the 10th centile at 40 weeks gestation is $34 \mathrm{~cm}$ and the and 90th centile is $38 \mathrm{~cm}$. This narrow range of SFH measurements is probably because the customised SFH chart was developed for a woman of Indian origin with a BMI of $21.8 \mathrm{~kg} / \mathrm{m}^{2}$ and residing in UK, while the main SFH chart constructed from the current study includes women with BMIs varying from $18.5 \mathrm{~kg} / \mathrm{m}^{2}$ to $25 \mathrm{~kg} / \mathrm{m}^{2}$ [11].

Many fundal height charts show linear SFH growth until about 36-38 weeks, after which the curve flattens. However most of these SFH charts have been based on menstrual dates, and it has been postulated that this may cause artificial flatting of the growth curve at term [16]. Menstrual dating errors have been shown to have a tendency to overestimate the length of gestation, resulting in birth weights at term being spread across a wider range. By contrast, routine ultrasound-dated birthweight charts have not demonstrated such flattening at term [17]. Our chart also did not show flattening towards term. All study participants were dated by first trimester ultra-sonographic fetal CRL measurement. Although this is the common clinical practice, it must be appreciated that this method does not consider the inherent biological variability and it has been suggested that it would be unscientific to presume that all fetuses with a given CRL will be of the same gestational age [15]. The main limitation of this study is that we did not look at inter- and intra-observer variation in SFH measurement. However, good reproducibility of SFH measurements have been reported [7].

It is expected that the SFH will be plotted on customised charts in order to detect longitudinal growth 
deviations. However, the SFH measurements are usually recorded as a number against the gestational age in the antenatal record. A recently concluded Sri Lankan multicenter audit on appropriate use of SFH charts in antenatal records showed that the use of SFH charts is suboptimal in most parts of the country [19]. SFH measurement below the tenth centile at a given occasion has high sensitivity (86\%) to predict low birth weight [20]. So, it is useful to chart SFH measurement on charts based on cross-sectional data to assess the fetal size.

BMI is probably the most significant factor that would influence fetal size and the $\mathrm{SFH}$, and $\mathrm{SFH}$ measurements tend to be systematically smaller among women with a low BMI while it tends to be larger among women with a high BMI, compared to those with a normal BM [17]. These effects of BMI on the SFH measurement should be consi-dered wheninterpreting SFH measurements in clinical practice. The development of a SFH chart for use in pregnant women with low BMI, is urgently needed.

\section{Acknowledgements}

We acknowledge the guidance and support of Prof. Malik Goonewardene in presentation of the results and editing this manuscript.

\section{Conflicts of interest}

There are no conflicts of interest.

\section{References}

1. Silver RM, Varner MW, Reddy U, et al. Work-up of stillbirth: a review of the evidence. Am J Obstet Gynecol 2007; 196: 433-44.

2. National Collaborating Centre for Women's and Children's Health, commissioned by the National Institute for Clinical Excellence. Antenatal Care: Routine Care for the Healthy Pregnant Woman 2008.

3. Royal College of Obstetricians and Gynaecologists. Greentop Guideline No. 31, The Investigation and Management of the Small-for-Gestational-Age Fetus. 2013.

4. Robert Peter J, Ho JJ, Valliapan J, Sivasangari S. Symphysial fundal height (SFH) measurement in pregnancy for detecting abnormal fetal growth. Cochrane Database Syst Rev 2015; 9: CD008136.

5. Arulkumaran S, Symonds IM, Fowlie A, eds. Oxford handbook of Obstetrics and Gynaecology. 1st ed. Oxford: Oxford University Press, 2005.

6. Beazley JM, Underhill RA. Fallacy of the undal height. BMJ 1970; 4: 404-6.
7. Bailey SM, Sarmandal P, Grant JM. A comparison of three methods of assessing inter-observer variation applied to measurement of the symphysis-fundal height. Br J Obstet Gynaecol 1989; 96:1266-71.

8. Papageorghiou AT, Ohuma EO, Altman DG, et al. International standards for fetal growth based on serial ultrasound measurements: the Fetal Growth Longitudinal Study of the INTERGROWTH-21st Project. Lancet 2014; 384: 869-79.

9. Gardosi J, Francis A. Controlled trial of fundal height measurement plotted on customised antenatal growth charts. BJOG 1999; 106: 309-31.

10. MoghaddamTabrizi F, Saraswathi G. Maternal anthropometric measurements and other factors: relation with birth weight of neonates. Nutr Res Pract 2012; 6: 132-7.

11. Shamawama KH, Goonewardene IM, Perera YA. Customised symphysio fundal height charts. Ceylon Med J 2012; 57: 159-65.

12. Robinson HP, Fleming JE. A critical evaluation of sonar “crown rump length” measurements. BJOG 1975; 82: 702-10.

13. Altman DG, Chitty LS. Charts of fetal size: 1 . Methodology. BJOG 1994; 101: 29-34.

14. Morse K, Williams A, Gardosi J. Fetal growth screening by fundal height measurement. Best Pract Res Clin Obstet Gynaecol 2009; 23: 809-18.

15. Villar J, Altman DG, Purwar M, Noble JA, Knight HE, Ruyan P, Cheikh Ismail L, Barros FC, Lambert A, Papageorghiou AT, Carvalho M. The objectives, design and implementation of the INTERGROWTH 21st Project. BJOG 2013; 120: 9-26.

16. Alexander GR, Himes JH, Kaufman RB, Mor J, Kogan M. A United States national reference for fetal growth. Obstet Gynecol 1996; 87: 163-8.

17. Wilcox M, Gardosi J, Mongelli M, Ray C, Johnson I. Birth weight from pregnancies dated by ultrasonography in a multicultural British population. BMJ 1993; 307: 588-91.

18. Calvert JP, Crean EE, Newcombe RG, Pearson JF. Antenatal screening by measurement of symphysis-fundus height. BMJ 1982; 285: 846-9.

19. Palihawadana TS, Wasalthilaka C, Dias T. The apt use of symphysio-fundal height chart during antenatal follow up: A multicenter audit. Sri Lanka J Obstet Gynaecol 2015; 4: 96-8.

20. Belizan JM, Villar J, Nardin JC, Malamud J, De Vicurna LS. Diagnosis of intrauterine growth retardation by a simple clinical method: measurement of uterine height. Am J Obstet Gynecol 1978; 131: 643-6. 